\title{
Centrifuge modelling of drawdown seepage in tailings storage facilities
}

\author{
CTS Beckett The University of Western Australia, Australia
}

AB Fourie The University of Western Australia, Australia

\begin{abstract}
Uncertainties surrounding seepage behaviour are a key issue raised in tailings storage facility (TSF) operation. Poor seepage management can result in negative environmental impacts, costly remediation or even embankment failure and, in the context of mine closure, long term liabilities and/or legacy site issues. In particular, recovery pumping rates must be maintained for sufficient time to capture seepage both during operation and after closure during reservoir drawdown.

Seepage analyses for TSF design commonly assume isotropic or, at best, anisotropic homogeneous material properties. However, layering during deposition, consolidation and swelling on drying and wetting create a seepage environment far more complex than these assumptions suggest. Improved modelling is required to increase analysis confidence.

Centrifuge modelling allows geotechnical phenomena to be investigated using scale models under representative stress conditions. However, precious few examples exist for seepage modelling using this technique. This paper briefly discusses modelling equipment development for use with The University of Western Australia (UWA) beam geotechnical centrifuge. Results for seepage during reservoir drawdown, simulating facility closure, are then presented for a layered, heterogeneous embankment model, as compared to predictions made by commercial analysis software. Findings are used to comment on the implication of simplifying analysis assumptions on drawdown time and flowrate calculations.
\end{abstract}

\section{Introduction}

The purpose of a tailings storage facility's (TSF) closure strategy is to ensure that it lasts in perpetuity without causing significant damage to the environment. Part of this strategy is control of seepage water to prevent contamination of, or excessive flow into, surface waters or the natural groundwater system. Understanding TSF seepage behaviour is essential to design seepage control systems appropriately.

Seepage analyses for TSF design commonly consider tailings deposits to be either isotropic or anisotropic homogeneous materials. This assumption is at odds with results from numerous piezocone field testing programmes (e.g. Williams \& Jones 2005), which instead show that distinct layering occurs during tailings deposition. Although thin, these layers can have a disproportionate effect on the seepage regime (Chang et al. 2011). For example, Amoah et al. (2006) found that layer void ratio $(e)$ and hydraulic conductivity $\left(k_{\text {sat }}\right)$ varied significantly depending on deposition environment, due to summer drying. In particular, $k_{\text {sat }}$ varied by an order of magnitude between the upper cracked layers and the underlying tailings body. Assuming homogeneous conditions for such a structure will lead to significant differences in predicted performance.

Modern numerical analysis packages, for example ABAQUS, can accommodate time and process dependent model material parameters. However, it is unrealistic to expect that such packages be adopted by industry as they require expert training and experience. Rather, the validity of idealised seepage scenarios through homogeneous (anisotropic or not) materials must be assessed. In this paper, we demonstrate discrepancies that arise between drawdown seepage analyses performed using commercial software (GeoStudio SEEP/W), using assumptions discussed above and experimental results obtained via geotechnical centrifuge modelling for heterogeneous materials. Findings are used to comment on implications when calculating 
likely drawdown times and flow rates and to provide benchmark data upon which existing models can be improved.

\subsection{Centrifuge modelling}

Geotechnical centrifuge modelling is a powerful technique which tests scaled models under stress conditions representative of those at full scale by accelerating them to many times Earth's gravity. For geometric and stress similitude, model dimensions are $n$ times smaller than the equivalent prototype, where $n$ is the acceleration scale factor (i.e. if testing at 100 times Earth's gravity, $n=100$ and the model is 100 times smaller than at full scale). The 'prototype' is a theoretical replica or simplification of the full scale structure, designed to capture the pertinent phenomena. Other experimental parameters affected by accelerating the model above Earth's gravity are shown in Table 1.

Table 1 Centrifuge seepage modelling scaling laws. $\boldsymbol{X}^{*}=\boldsymbol{X}_{m} / \boldsymbol{X}_{\boldsymbol{p}}$, where $\boldsymbol{X}_{m}$ and $\boldsymbol{X}_{\boldsymbol{p}}$ are parameter values in the model and prototype respectively (Madabhushi 2014)

\begin{tabular}{cc}
\hline Parameter & Scale factor \\
\hline Acceleration, $g^{*}$ & $n$ \\
\hline Length, $\lambda^{*}$ & $1 / n$ \\
\hline Angle of friction, $\phi^{\prime *}$ & 1 \\
\hline Apparent cohesion, $c^{\prime *}$ & 1 \\
\hline Soil density, $\rho^{*}$ & 1 \\
\hline Effective stress, $\sigma^{\prime *}$ & 1 \\
\hline Hydraulic conductivity, $k^{*}$ & 1 \\
\hline Hydraulic gradient, $i^{*}$ & $n$ \\
\hline Pore pressure, $u^{*}$ & 1 \\
\hline Seepage velocity, $v^{*}$ & $n$ \\
\hline Flow rate, $\dot{Q}^{*}$ & $1 / n$ \\
\hline Time (kinematic), $t^{*}$ & $1 / n^{2}$ \\
\hline
\end{tabular}

A key advantage of centrifuge modelling is that the majority of soil parameters have a scale factor of 1 . Therefore, the same soil as present in the field can be used in the centrifuge. Very long processes can also easily be accommodated; at $n=100,50$ years at prototype scale is equivalent to only 44 hours for the model. However, seepage phenomena, which are time-dependent, are affected. Significantly, seepage velocities in the centrifuge are $n$ times higher in the model than in the prototype. Flow velocities must therefore be selected to prevent the formation of turbulent flow regimes, which are not representative of natural groundwater flows of interest. Furthermore, as the gravitational field in a centrifuge is generated via radial acceleration, gravity scaling is not equal at all points within a model. This point will not be elaborated here, however is discussed in Beckett et al. (2015) and is critical to relate measured model parameters back to the full scale prototype accurately.

\section{Experimental programme}

This paper presents results for reservoir drawdown testing on a layered, heterogeneous tailings embankment model. Methods used in this study were verified in Beckett et al. (2015) for a homogeneous model, tested under steady state and drawdown seepage conditions. Detailed discussion of technique development is provided in that work; a summary is provided here for convenience. 


\section{$2.1 \quad$ Equipment}

Specialised equipment was designed in-house to test embankment models in the beam centrifuge. Equipment design was based on that used in Sutherland and Rechard (1984) and Resnick and Znidarčić (1990) and comprises a model container, housed within a larger centrifuge 'strongbox', as shown in Figure 1. A five megapixel camera views the model through a $25 \mathrm{~mm}$ thick Perspex screen, into which markers were embedded to provide a grid of known coordinates. Pressure transducers mounted underneath the model container (protected by sintered bronze filters) monitor water head levels within the model and flanking reservoirs. The reservoirs are separated from the model by reinforced porous screens held within a rigid frame. The reservoirs are visible through the Perspex screen to confirm water levels using the camera whilst in flight. A syringe pump is attached to the downstream reservoir (DSR) to control downstream head levels and measure exit flow rates during testing. A remotely-controlled valve allowed the pump to be purged once it was full. Upstream reservoir (USR) water level is controlled by varying water flow into the model.

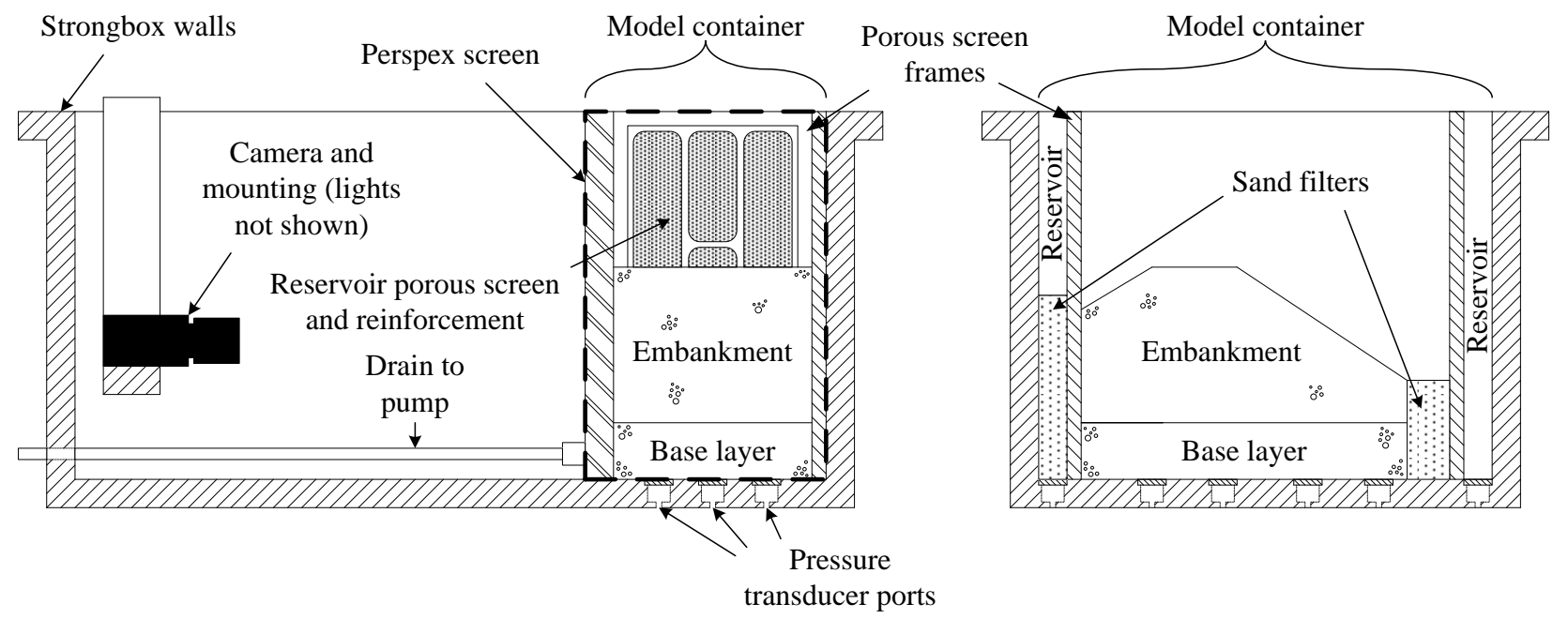

Lengthwise section through strongbox

Crosswise section through strongbox and model container

Figure 1 Sectional views through centrifuge strongbox showing principal equipment components (not to scale) (modified from Beckett et al. 2015)

\subsection{Model design and manufacture}

The model used in this investigation is shown in Figure 2. The model comprised two material strata, simulating an embankment built on a permeable substrate. The embankment stratum was formed from pure silt and the base stratum from a 90:10 silt:fine sand mix. These materials were selected to produce marginally heterogeneous materials of similar seepage characteristics to real tailings (e.g. those used in Sutherland and Rechard (1984)). A sand filter was used downstream of the model to prevent fine particle migration into the DSR porous screen. A method to test filter material suitability and integrity using a 'desktop' centrifuge was discussed in Beckett et al. (2015).

Each stratum was deposited as a slurry (approximately 50\% solids content) in thin layers until the required height was reached. Material remained saturated between pours (i.e. drying due to solar exposure was not simulated). The base stratum was left to settle for 24 hours prior to pouring the embankment stratum to prevent mixing at the interface. The slurries were separated from the sand filter by a removable plastic divider, which was retracted once the layers had been poured. After settling, the model was inundated with water and consolidated at an acceleration of $100 \mathrm{~g}$ (i.e. $n=100$ at the model base) for 12 hours (equivalent to roughly 13.5 years by Table 1 ). Water was then gradually pumped out of the model prior to gravity turn-off and the model removed from the centrifuge. The embankment stratum was hand-trimmed to represent typical TSF geometry; here, an upstream and downstream slope to simulate a tailings beach and the main embankment slope respectively. 


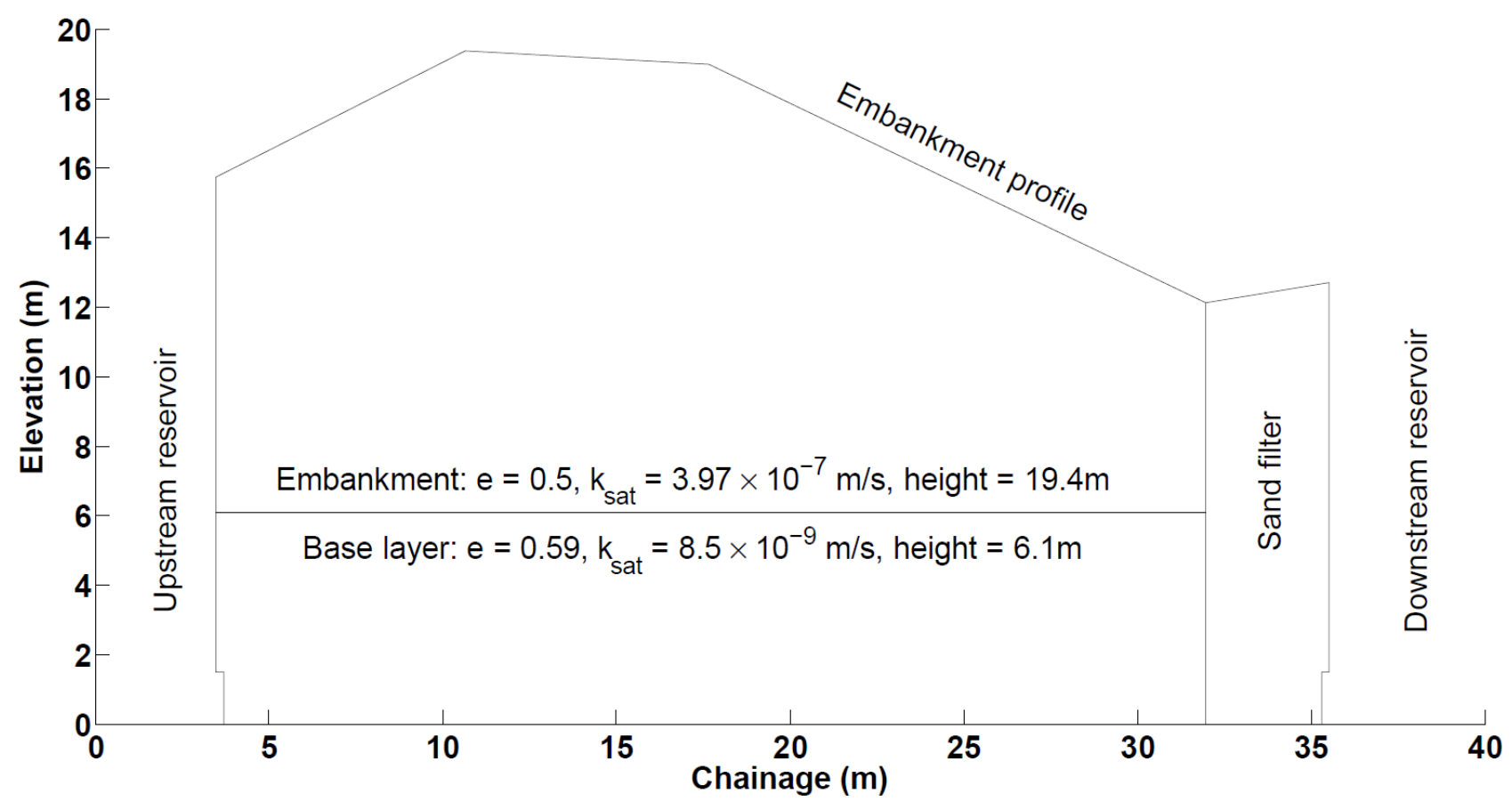

Figure 2 Centrifuge model and assumed homogeneous material parameters (equivalent prototype dimensions)

It is noted that the method of pouring material vertically into the mould and trimming after consolidation results in an overconsolidation ratio (OCR) greater than one along the trimmed material surfaces, which is not representative of reality. An alternative construction method, where the slurry was poured in the out-of-plane direction in Figure 2 into a mould of the correct shape, was investigated to alleviate this issue. However, debris caught between the container's components prevented it from being sealed. The method of pouring the material vertically into the pre-sealed container was therefore adopted.

\subsection{Centrifuge drawdown testing}

All drawdown tests were conducted at $n=100$. At $n=100$, the equivalent model dimensions are roughly $19 \mathrm{~m}$ high ( $6 \mathrm{~m}$ base layer depth, $13 \mathrm{~m}$ embankment height) by $30 \mathrm{~m}$ wide, as shown in Figure 2 . These dimensions are significantly smaller than those present in full-scale TSFs, whose half-widths can be of the order of $500 \mathrm{~m}$. The use of a truncated profile was necessary to fit the model within the centrifuge strongbox whilst testing measureable hydraulic gradients. Truncation of the model required the use of steeper slope angles; acceleration was therefore gradually increased to the target level over the course of roughly one hour to avoid slope failure due to excess pore pressure development during gravity turn-on.

Drawdown testing was initiated from steady-state seepage conditions. USR water level was controlled by varying the water flow rate into the model. The DSR was maintained at a level <USR (to impose a hydraulic gradient) using the automated pumping system, whose rate was continually adjusted in a closed loop using the analogue signal from the DSR pressure transducer. Reservoir levels were selected to induce ponding roughly half way up the model upstream slope. Once established, steady-state conditions were maintained for one full pumping cycle (i.e. one full stroke of the syringe). Flow to the USR was then terminated to initiate drawdown whilst maintaining the same DSR water level. A total of three drawdown tests were conducted; for Test 1, the DSR level was maintained above the height of the base stratum. Tests 2 and 3 DSR water levels were below the embankment-base interface.

\subsection{Numerical modelling}

As discussed above, it is common to assume homogeneous material properties when analysing TSF seepage behaviour. GeoStudio SEEP/W was used to evaluate differences arising between predicted and measured 
model performance due to these assumptions. Constant Rate of Strain (CRS) and 'desktop' centrifuge testing were used to characterise model material properties for input into SEEP/W analyses.

\subsubsection{CRS testing}

CRS testing uses a low, constant vertical strain rate to yield continuous material consolidation data (as opposed to incremental data obtained from more traditional testing techniques, for example the oedometer or Rowe cell). Pore pressure is constantly monitored during consolidation to ensure drained conditions and to calculate $k_{\text {sat }}$. CRS results for the base stratum (silt-sand mix) are shown in Figure 3 . The sample was preconsolidated to $150 \mathrm{kPa}$.

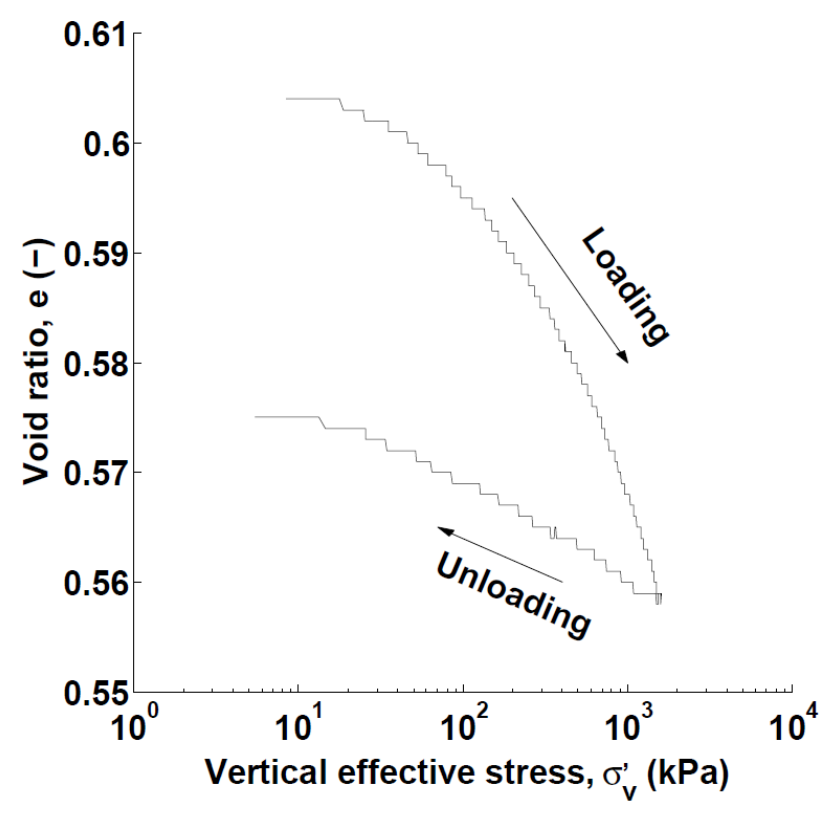

(a)

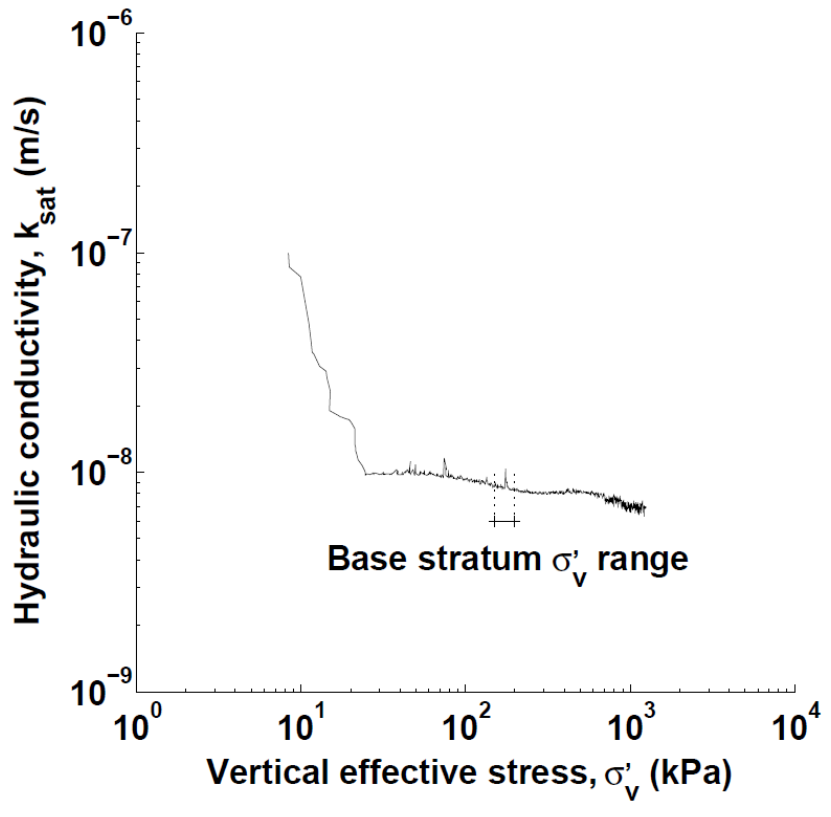

(b)

Figure 3 CRS results for the base stratum (silt-sand mix): (a) change in void ratio on loading and unloading; (b) change in $\boldsymbol{k}_{\text {sat }}$ with increasing $\boldsymbol{\sigma}_{v}^{\prime}$

Figure 3 shows little variation in void ratio with changes in vertical effective stress $\left(\sigma_{v}^{\prime}\right)$. However, $k_{s a t}$ reduces by an order of magnitude between 8 and $20 \mathrm{kPa}$. Although a significant change, for material consolidation at $n=100$, it can be estimated that the model base layer is subjected to effective stresses of between 150 to $200 \mathrm{kPa}$ (as indicated in Figure 3(b)), so that this rapid initial variation does not affect material behaviour in this stratum. A constant value of $k_{\text {sat }}=8.5 \times 10^{-9} \mathrm{~m} / \mathrm{s}$ was therefore assumed.

\subsubsection{Desktop centrifuge}

The desktop centrifuge is a Clements model Orbital 420, modified to accommodate geotechnical samples. As for larger centrifuges, the desktop centrifuge takes advantage of the varying gravitational field with radius to apply a range of effective stresses over a sample's length (Kayabali \& Ozdemir 2012). Pore pressure transducers mounted in the base of the four centrifuge canisters indicate when consolidation has ceased. Material void ratio and corresponding effective stress are determined from sample slices taken from known depths and distances from the centrifuge centre of rotation (Reid et al. 2012).

Desktop centrifuge results for pure silt and the silt-sand mix (two tests per material) are shown in Figure 4. Pure silt void ratio (Figure 4(a)) was lower at zero effective stress than the silt-sand mix (Figure 4(b)), which is consistent with the former's finer particle size. Pure silt showed little change in void ratio up to $30 \mathrm{kPa}$, whereupon it rapidly consolidated to achieve a minimum void ratio of 0.5 for effective stresses above $50 \mathrm{kPa}$. The silt-sand mix showed a consistent consolidation gradient up to $60 \mathrm{kPa}$, whereupon it also 
reached a minimum void ratio of 0.5 , suggestibly due to the large silt fraction dominating the maximum achievable particle packing.

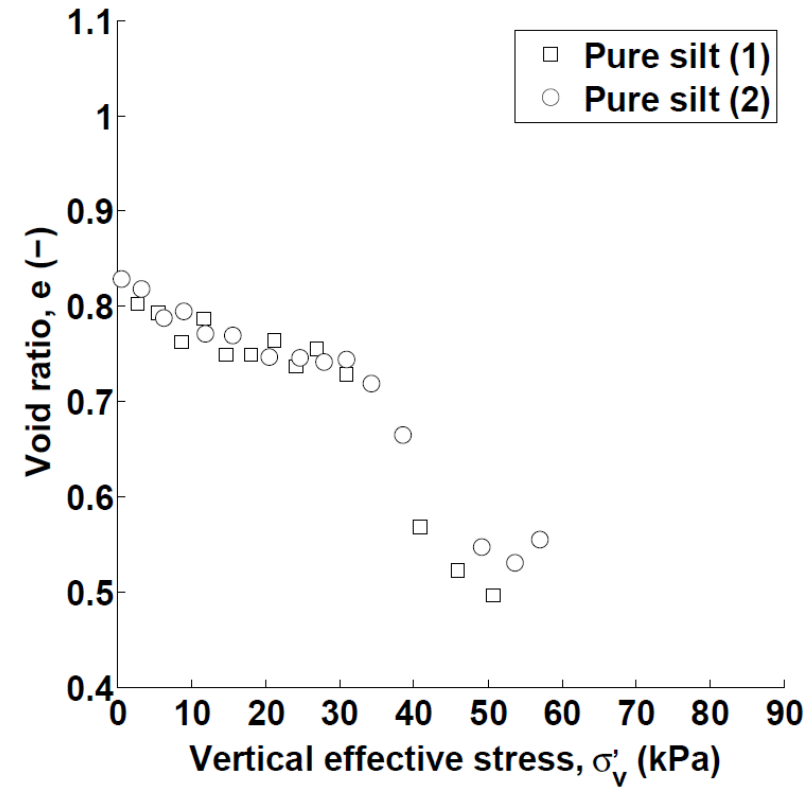

(a)

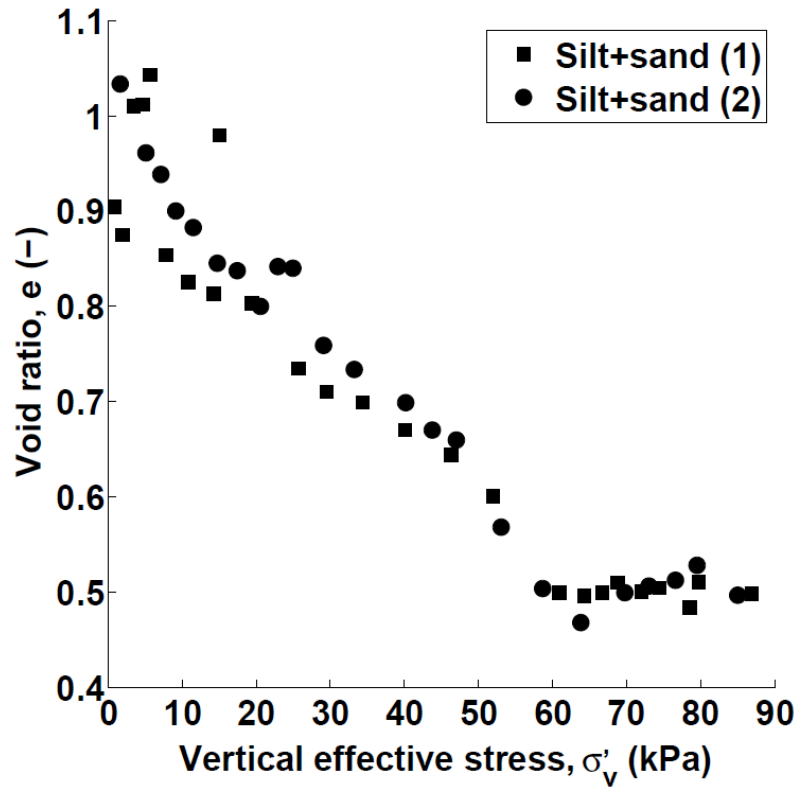

(b)

Figure 4 Consolidation of pure silt (embankment stratum (a)), and silt-sand mix (base stratum (b)), using the desktop centrifuge (two tests per material)

Desktop centrifuge results shown in Figure 4(b) for the silt-sand mix are in rough agreement with CRS results shown in Figure 3(a). Void ratios at zero effective stress in Figure 4(b) are initially higher than those found via CRS, due to the lack of preconsolidation. However, a minimum void ratio is reached at a far lower effective stress than found in CRS. Given the complex stress environment induced by the desktop centrifuge, it might be that samples are subjected to higher stresses than those calculated using just their distance from the centre of rotation; the significance of this result is still under investigation and will be discussed in an upcoming paper.

Effective stresses in the embankment during consolidation (i.e. prior to shaping the model) can be estimated to range between 0 and $150 \mathrm{kPa}$. Figure 4(a) shows that void ratio, and so hydraulic conductivity, varies significantly over this range. A value of $e=0.5$ at the average effective stress of roughly $75 \mathrm{kPa}$ was assumed for the embankment stratum. In the absence of measured data, $k_{\text {sat }}$ for the silt layer was estimated via

$$
k_{\text {sat }}=2.4622\left(\frac{d_{10}^{2} e^{3}}{1+e}\right)^{0.7825}=3.97 \times 10^{-7} \mathrm{~m} / \mathrm{s}
$$

where $d_{10}=3 \mu \mathrm{m}$ is the $10 \%$ passing particle diameter for the silt (in $\mathrm{mm}$ in Equation (1)) and $k_{\text {sat }}$ is given in $\mathrm{cm} / \mathrm{s}$. Equation (1) has been shown to be suitable for low-plasticity soils with $3 \mu \mathrm{m}<d_{10}<3 \mathrm{~mm}$ and $0.3<e<1.0$, as is used here (Chapuis 2012). Tests to confirm $k_{\text {sat }}$ for the pure silt are still ongoing. Note that as $e=0.5$ is the minimum void ratio expected for the embankment layer, then $k_{\text {sat }}=3.97 \times 10^{-7} \mathrm{~m} / \mathrm{s}$ is also the minimum expected hydraulic conductivity. Again, the significance of this assumption is discussed in the following sections.

CRS results from Figure 3(a) were used for the base stratum as desktop centrifuge data was not available for the anticipated effective stress levels. $k_{\text {sat }}=8.5 \times 10^{-9} \mathrm{~m} / \mathrm{s}$ was assumed for the base stratum. 


\section{$3 \quad$ Results and discussion}

\subsection{Drawdown head levels}

Example measured and predicted changes in head level at selected model times following reservoir drawdown are shown in Figure 5 for Test 1. Steady-state head levels (i.e. at zero seconds) at the start of each test are shown in Figure 6. Head levels are predicted from known transducer locations within the strongbox and iteratively-calculated water levels, as discussed in Beckett et al. (2015). Drawdown was modelled in SEEP/W by applying transient head boundary conditions to the upstream model face, incorporating seepage face review. Changes in measured USR head with time were used as the upstream SEEP/W boundary condition function. A comparison between measured and predicted head levels for all three tests (paired by lengthwise coordinate and assessed at model times given in Figure 5) is shown in Figure 7. The line of equality represents perfect agreement between predicted and measured values; results above the line of equality are overpredicted, whilst those below are underpredicted.

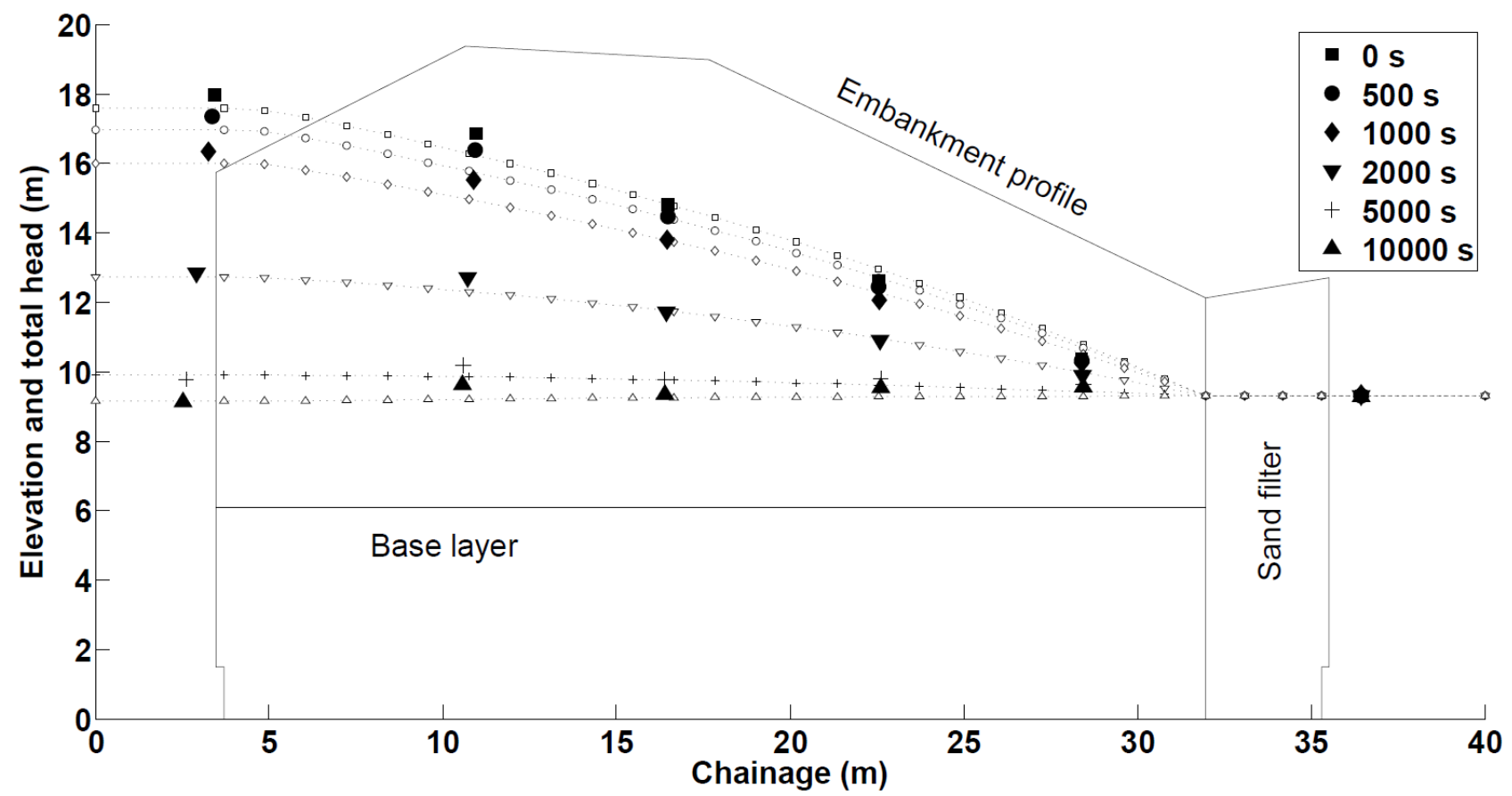

Figure 5 Change in embankment head level with time following termination of U/S flow for Test 1.

Note selected times are in model scale. Black markers show experimental results.

White markers show predicted head levels from SEEP/W

Figure 7 shows differences between measured and predicted head levels of up to and over $1 \mathrm{~m}$. This is significantly larger than the $<0.3 \mathrm{~m}$ error found in Beckett et al. (2015) for the accuracy of this equipment when testing homogeneous materials. In general, head levels at lower elevations are overpredicted, whilst those at higher elevations (i.e. nearer the upstream boundary) are underpredicted. This is consistent with the expected decrease in void ratio with depth through the embankment layer; at higher head levels, $e$ and $k_{\text {sat }}$ are higher than the average value for the layer, resulting in reduced flow resistance and higher head levels. As $e$ and $k_{\text {sat }}$ in a 'true' tailings material are likely to vary far more with effective stress, it is likely that such prediction errors will be magnified (Zhang et al. 2015). 


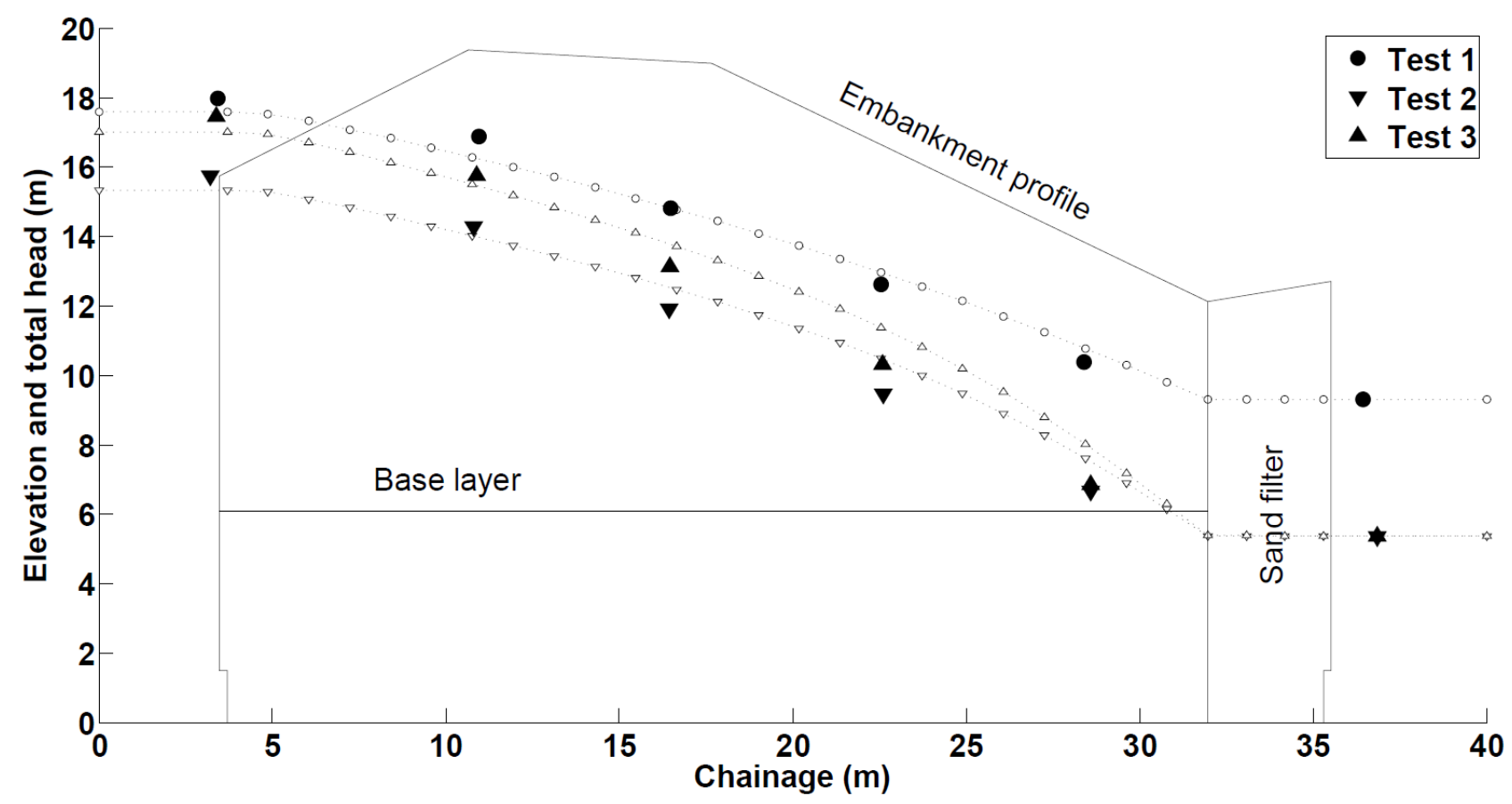

Figure 6 Steady-state seepage head levels at the start of each drawdown test. Black markers show experimental results. White markers show predicted head levels from SEEP/W

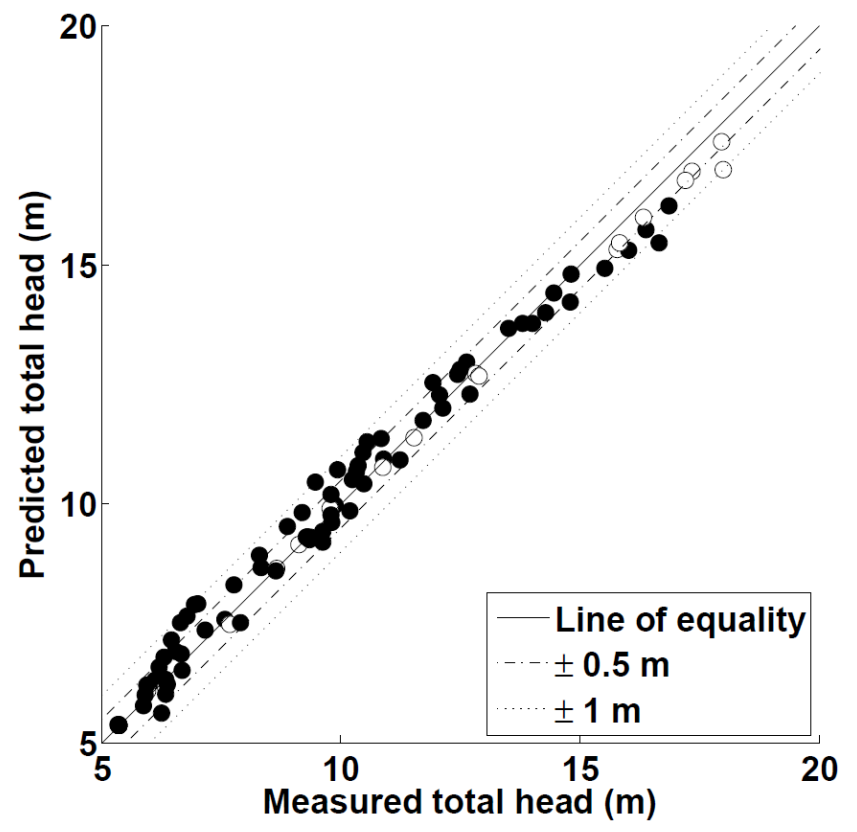

Figure 7 Comparison of predicted and measured head levels during drawdown for all tests. White markers $(O)$ show USR head levels

Although upstream head level was used as a boundary condition, Figure 5 shows that numerical values continually underpredict USR head level by a small margin. A similar error was encountered in Beckett et al. (2015) due to a short impermeable section at the base of the upstream porous screen and a distortion of the upstream equipotential lines. Equipotential lines for steady-state flow prior to drawdown during Test 1 are shown in Figure 8(a). The majority are perpendicular to the model base, so that base-mounted pressure transducers are able to detect the full range of head levels within the model. However, flow deviates around the foot of the USR porous screen frame so that head levels measured at the base of the model do 
not match those in the USR. A solution is to include a second sand filter upstream of the USR porous screen, as shown in Figure 8(b). This modification will be incorporated in future testing, but it is reported here to demonstrate the need to ensure that transducers are able to adequately detect model head levels. Notably, Figure 7 shows that USR head levels are always underpredicted by up to $0.5 \mathrm{~m}$, which agrees well with the $-0.5 \mathrm{~m}$ maximum detectable contour intercepting the base of the model at the upstream face in Figure 8(a).

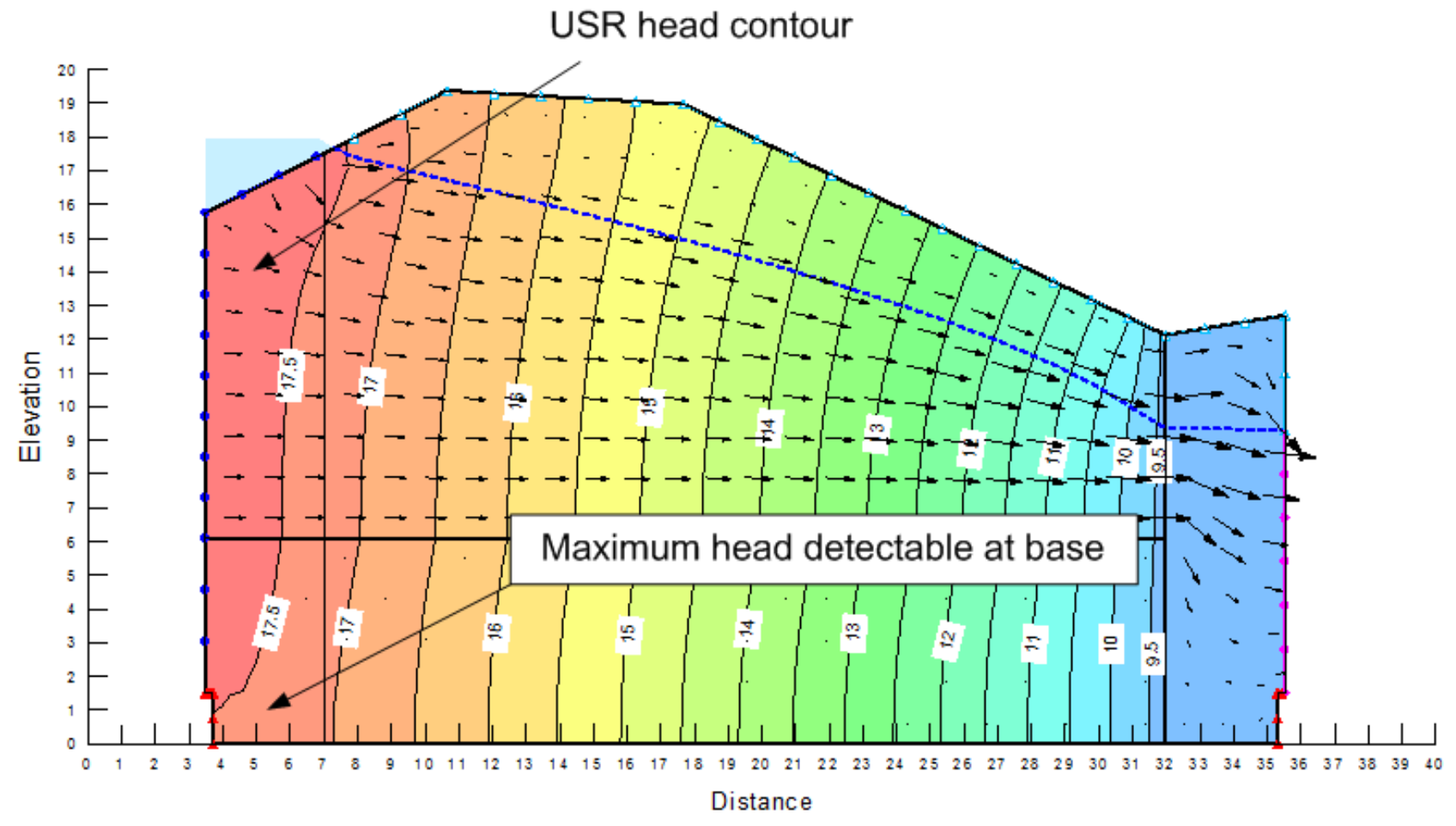

(a)

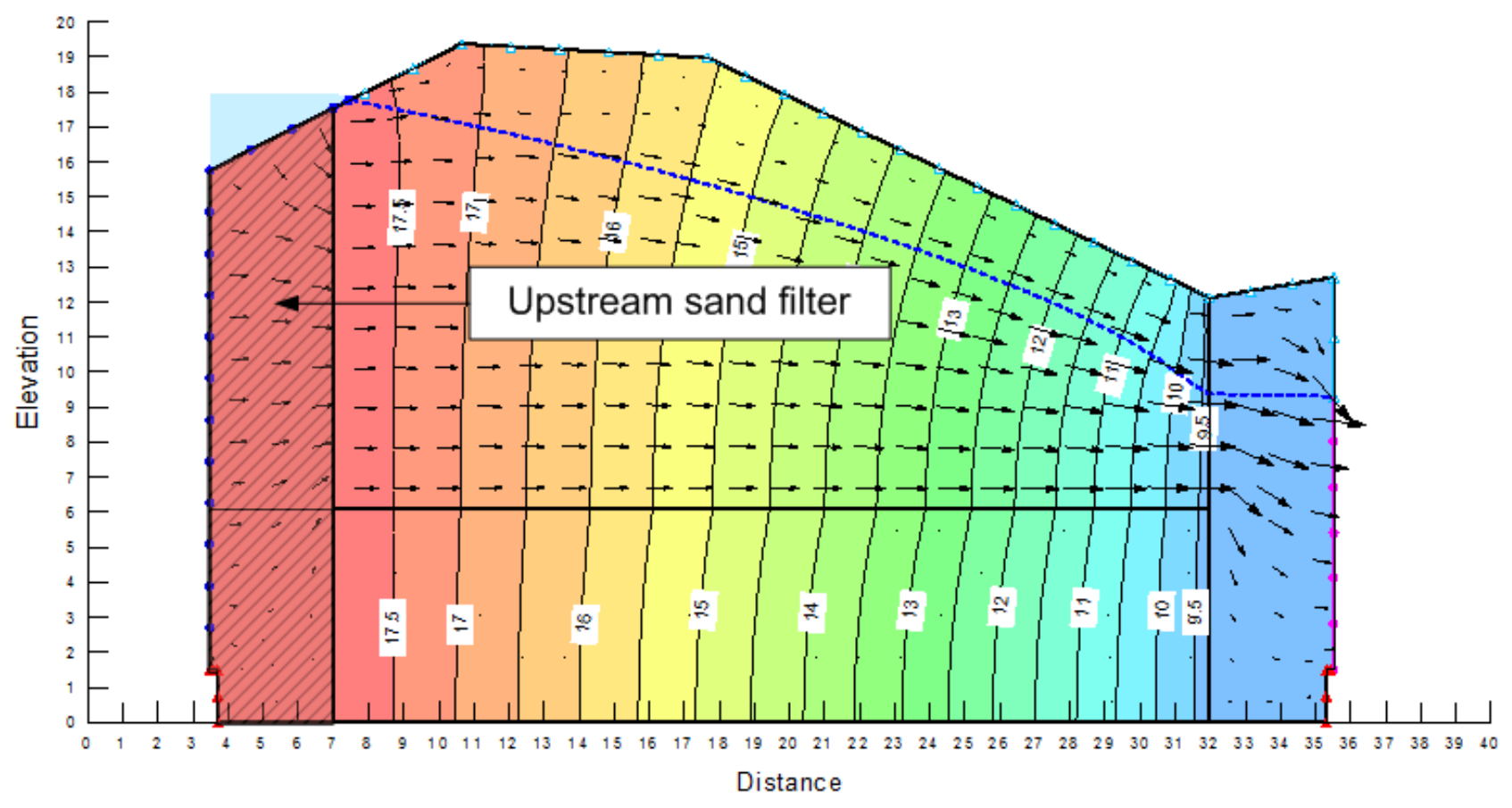

(b)

Figure 8 SEEP/W analyses for Test 1 at steady-state (see Figures 5 and 6): (a) without upstream sand filter; (b) upstream sand filter added. Dimensions in metres. Head contours in increments of $0.5 \mathrm{~m}$ 


\subsection{Seepage flow rates}

Flow rate from the DSR at a given time during steady state or drawdown can easily be calculated given the known syringe pump displacement rate and internal diameter $(50 \mathrm{~mm})$. Predicted and measured flow rates are compared in Figure 9 (prototype scale). The good agreement found for initial flow rates (i.e. immediately after steady-state) indicates that $k_{\text {sat }}$ values approximated using Equation (1) for the embankment material are acceptable. For Tests 1 and 2, drawdown was complete after roughly 700 equivalent full-scale days. Drawdown took approximately 1,000 equivalent full-scale days for Test 3 due to a higher initial hydraulic gradient. As discussed in Beckett et al. (2015), this is far quicker than would be expected for a full-scale TSF and is due to the truncated model profile.
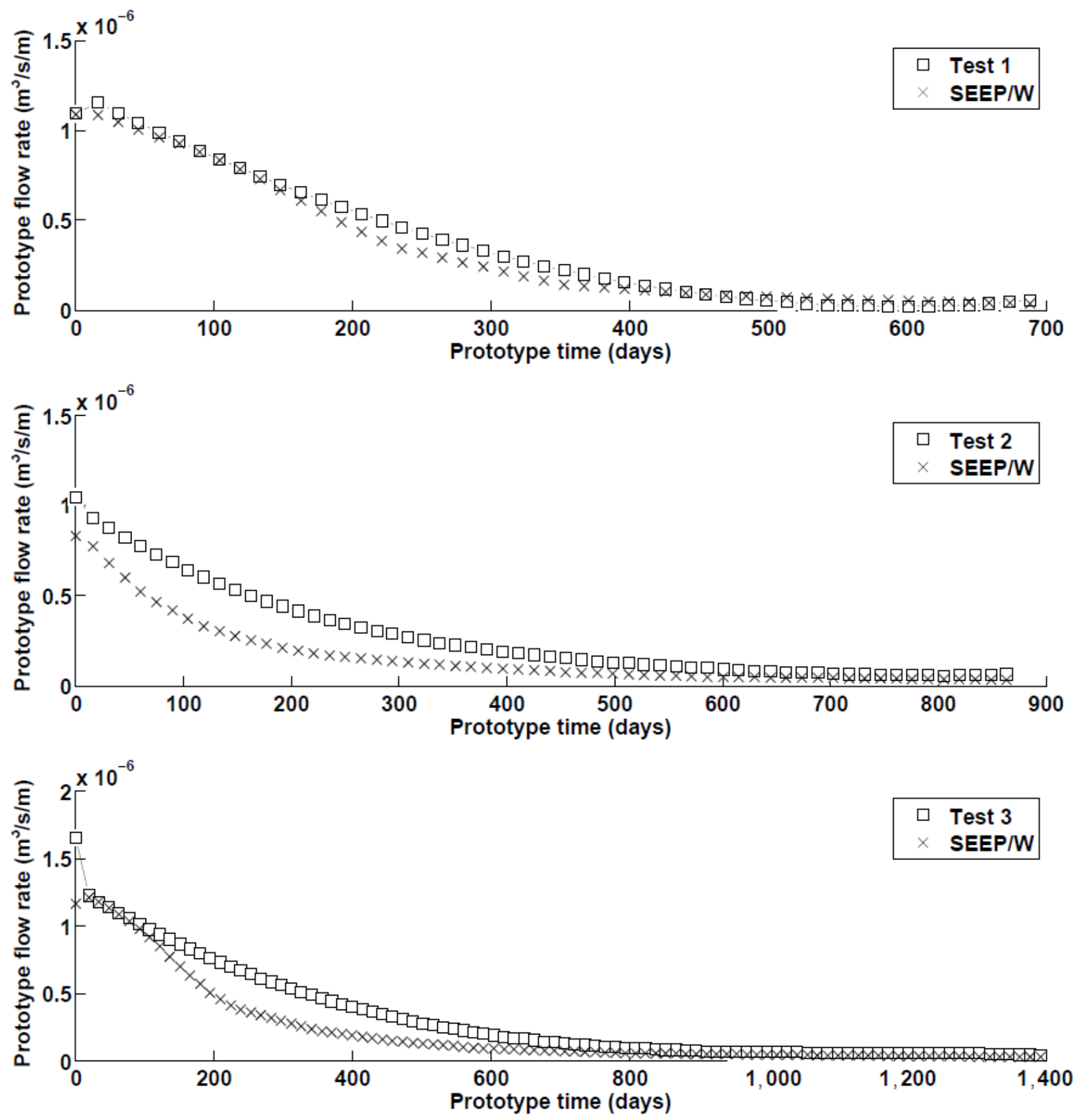

Figure 9 Drawdown seepage flow rates during Tests 1, 2 and 3

Figure 10 compares all measured and predicted flow rates, paired by drawdown time. Unlike head levels, which display under- and overprediction, flow rates are underpredicted for all tests. Underprediction is 
more significant for Tests 2 and 3 than for Test 1 ; as the initial phreatic surface for Tests 2 and 3 passes through the entirety of the embankment stratum and some of the underlying base stratum (Figure 6), results are more greatly affected by changes in $k_{\text {sat }}$ with depth.

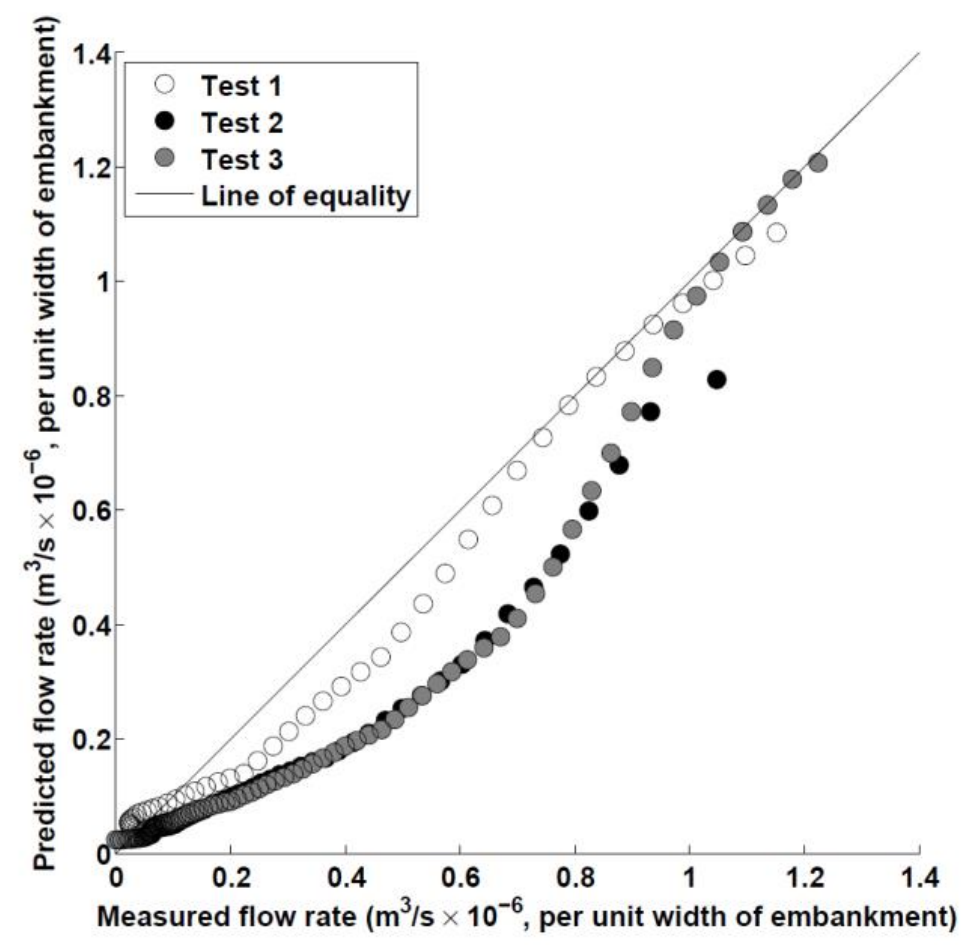

Figure 10 Predicted against measured drawdown seepage flow rates for Tests 1, 2 and 3

\subsection{Varying $k_{\text {sat }}$ in SEEP/W}

Based on the above discussion, the SEEP/W model was modified to include multiple material layers in the embankment stratum. The model and parameter values used in the analysis are shown in Figure 11. The model was divided into one stratum per $10 \mathrm{kPa}$ effective stress increment, calculated assuming vertical consolidation under saturated conditions. Layer $k_{\text {sat }}$ values were calculated using Equation (1) and results in Figure 3(a). Predicted and measured head levels and flow rates during drawdown for the modified embankment model are shown in Figures 12 and 13 respectively. 


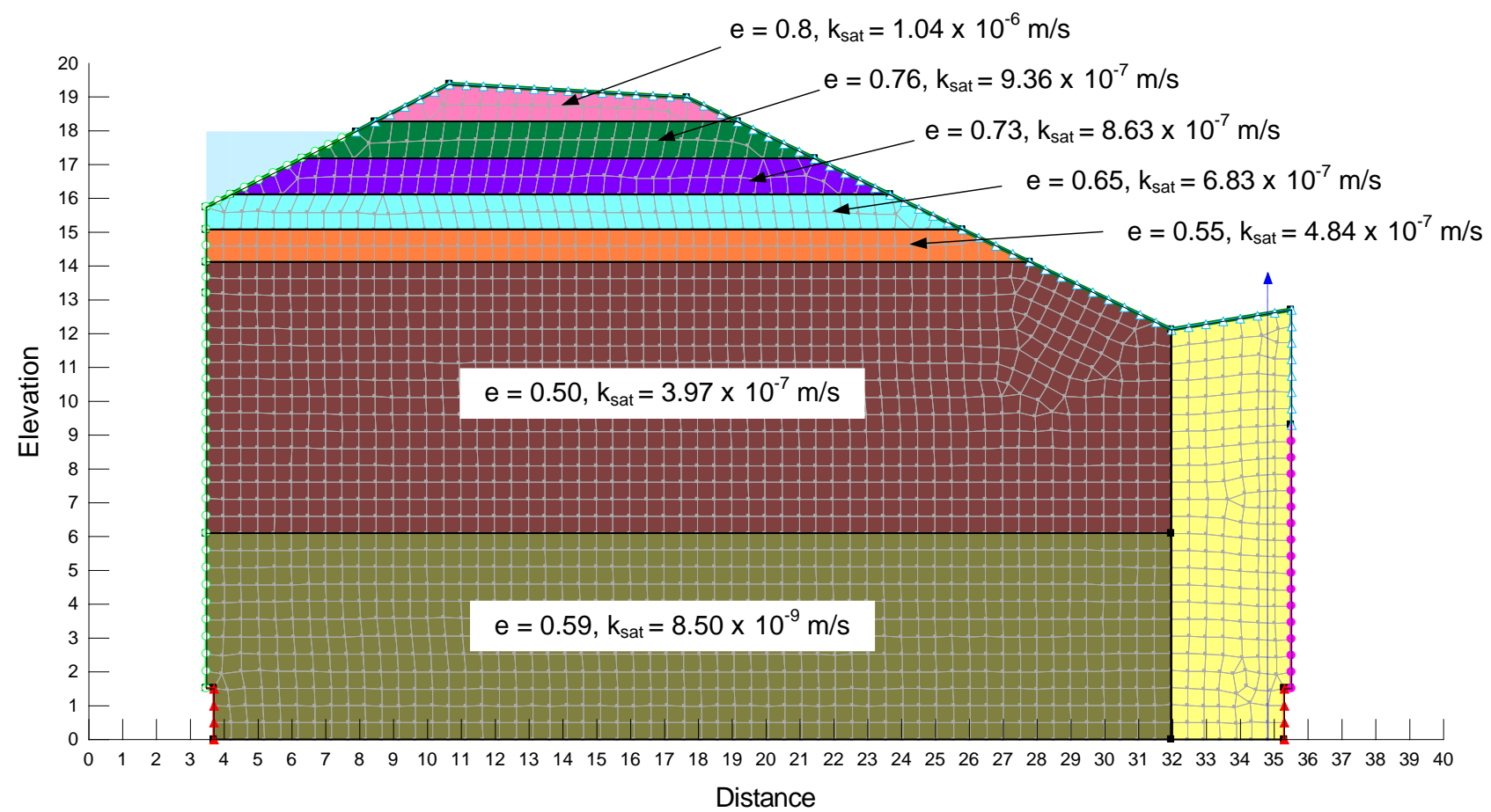

Figure 11 Layered SEEP/W model and parameter values (units in $\mathrm{m}$, element size $0.5 \mathrm{~m}$ )

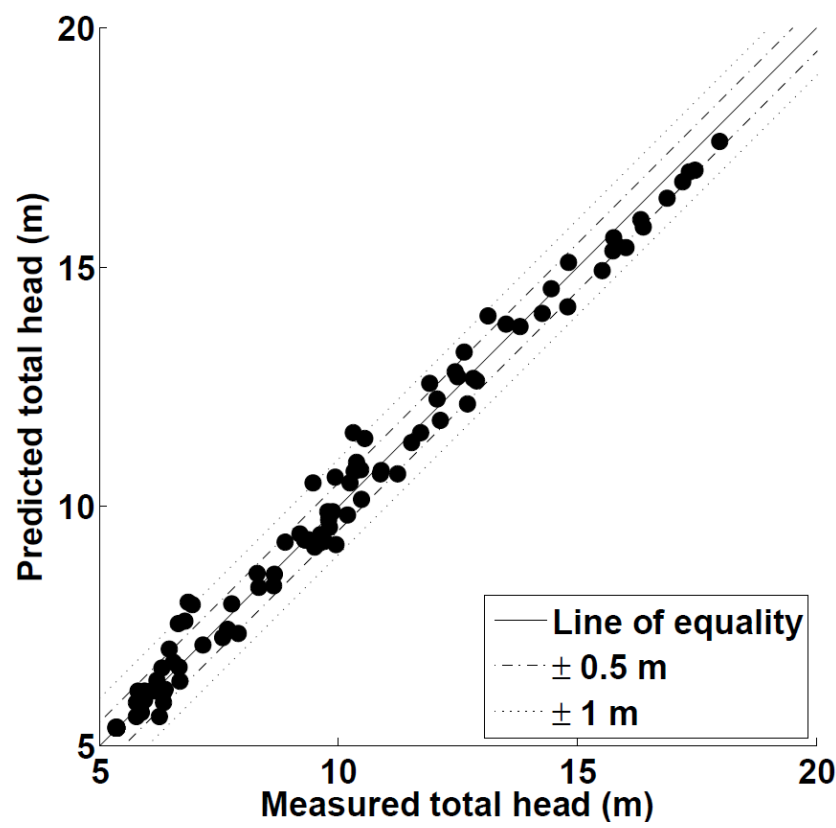

Figure 12 Comparison of predicted and measured layered model head levels during USR drawdown 


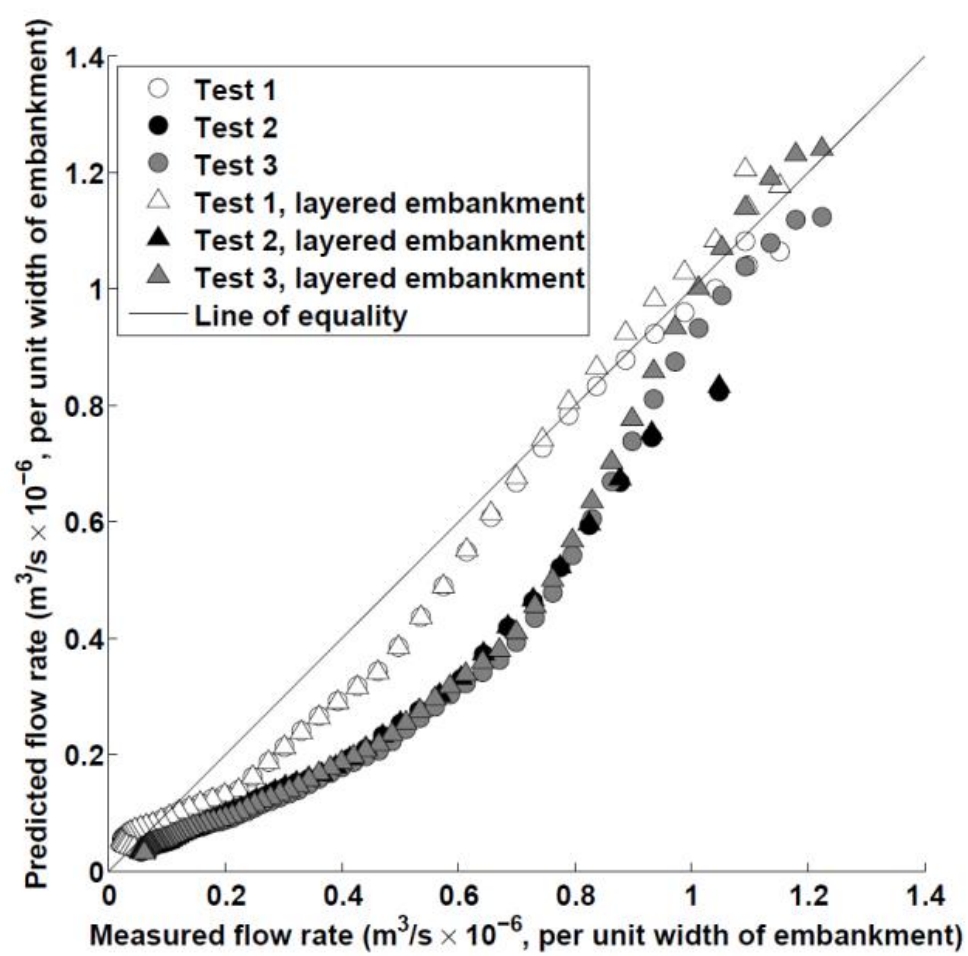

Figure 13 Comparison of predicted and measured layered model flow rates during USR drawdown

Predicted head levels in the modified model are similar to those presented in Figure 8 . As head levels are calculated from measured USR levels, similarity is to be expected. Figure 13 shows that the inclusion of higher $k_{\text {sat }}$ layers in the embankment improved predicted flow rate accuracy at higher elevations. Little difference was found between the two models for lower elevations; this is particularly evident for Test 2, where flow was largely through the lowest (unmodified) embankment layer. Notably, the greatest difference between predicted and measured flow rates in Figure 13 occurred around a predicted flow rate of $4 \times 10^{-7} \mathrm{~m}^{3} / \mathrm{s}$ for all tests. This corresponds to USR levels intersecting the upstream model face at the embankment mid-height (Figures 5 and 9), where $k_{\text {sat }}$ equals the assumed average value.

It is clear from Figures 12 and 13 that accommodating variations in $k_{\text {sat }}$ with depth improves model accuracy. Results in Figure 13 serve as a useful indicator for relating real seepage behaviour to that predicted using homogeneous material assumptions; actual flow rates are likely to be significantly greater than predicted values.

\section{Conclusion}

It is now well known that tailings are a heterogeneous material, and so are unlikely to be well characterised by homogeneous material assumptions. This paper presented an experimental investigation of drawdown times and flow rates for a heterogeneous model comprising a silt embankment overlying a silt-sand base stratum.

It has been shown that numerical analyses based on homogeneous material properties largely under and overpredicted head levels at higher and lower elevations respectively, but consistently underpredicted seepage flow rates. It was shown that these differences arose due to changing values of $e$ and $k_{\text {sat }}$ through the embankment layer which could not be captured in the software. Given that 'true' tailings display far greater variability in $e$ and $k_{s a t}$ with effective stress than those materials tested here, differences between predicted and actual performance of full-scale TSFs are likely to be more significant than those found here. This has potentially significant implications for the design of TSF closure strategies; underpredicted flow rates suggest that longer pumping times (or other forms of active treatment) may be required. 


\section{Acknowledgement}

The authors gratefully acknowledge funding awarded from the Minerals Research Institute of Western Australia (MRIWA) and from the P1087, Integrated Tailings Management Project, funded through AMIRA International by Anglo American, Freeport-McMoRan, Gold Fields, Total E\&P Canada, Newmont, Shell Canada Energy, BASF, Nalco and Outotec.

\section{References}

Amoah, N, Phillips, J \& Vlahos, S 2006, 'Investigation of hydrological behaviour of in situ bauxite residue for closure and rehabilitation design', in AB Fourie \& M Tibbett (eds), Proceedings of the First International Seminar on Mine Closure, Australian Centre for Geomechanics, Perth, pp. 441-451.

Beckett, CTS, Fourie, AB \& O'Loughlin, CD 2015, 'Centrifuge modelling of seepage through tailings embankments', International Journal of Physical Modelling in Geotechnics, in press, DOI: 10.1680/jphmg.14.00045.

Chang, N, Heymann, G \& Clayton, C 2011, 'The effect of fabric on the behaviour of gold tailings', Géotechnique 61(3), pp. 187-197.

Chapuis, RP 2012, 'Predicting the saturated hydraulic conductivity of soils: a review', Bulletin of Engineering Geology and the Environment, 71, pp. 401-434.

Kayabali, K \& Ozdemir, A 2012, 'Assessing the practicality of the centrifuge method for 1-D consolidation', Bulletin of Engineering Geology and the Environment, 71, pp. 735-745.

Madabhushi, G 2014, Centrifuge modelling for civil engineers, CRC Press, London.

Reid, D, Fourie, A, Watson, S, Jewell, R 2012, 'Accelerated consolidation testing of slurries using a desktop centrifuge', in A Fourie \& A Paterson (eds), Proceedings of the 15th International Seminar on Paste and Thickened Tailings (PASTE 2012), Australian Centre for Geomechanics, pp. 43-52.

Resnick, GS \& Znidarčić, D 1990, 'Centrifugal modeling of drains for slope stabilization', Journal of Geotechnical Engineering, 116, pp. 1607-1624.

Sutherland, H \& Rechard, R 1984, 'Centrifuge simulations of stable tailings dam', Journal of Geotechnical Engineering, American Society of Civil Engineers, 110, pp. 390-402.

Williams, D \& Jones, H 2005, 'Tailings storage facilities. In Advances in Gold Ore Processing', in BA Wills (ed), Developments in Mineral Processing, vol. 15, Elsevier, Amsterdam, pp. 729-752.

Zhang, Q, Yin, G, Wei, Z, Fan, X, Wang, W \& Nie, W 2015, 'An experimental study of the mechanical features of layered structures in dam tailings from macroscopic and microscopic points of view', Engineering Geology, 195, pp. 142-154. 